\title{
A PROMESSA E A AMEAÇA - O FUNCIONAMENTO DA VIOLÊNCIA COMO FERRAMENTA POLÍTICA NA BAIXADA FLUMINENSE
}

\section{Enderson Albuquerque*}

Professor das redes públicas municipais do Rio de Janeiro e Mesquita

Resumo: 0 presente artigo analisa o uso da violência como ferramenta para o estabelecimento de poder político nos municípios da Baixada Fluminense. Para tanto, analisamos desde o período do processo de formação territorial da região até sua atual configuração territorial. Essa análise conduziu ao entendimento de que em um primeiro momento a violência praticada na região tinha relação direta com questões fundiárias e comerciais. Em um segundo período ela passou a ser utilizada como elemento de coação pelo aparato de repressão do Regime Militar e, posteriormente, no período de redemocratização, a violência foi utilizada ao mesmo tempo como "promessa e ameaça" para alavancar o ingresso de agentes políticos nos poderes executivo e legislativos dos municípios baixadianos.

Palavras chave: Baixada Fluminense; violência; política

THE PROMISE AND THE THREAT - THE FUNCTIONING OF VIOLENCE AS A POLITICAL TOOL IN THE BAIXADA FLUMINENSE

Abstract: This article analyzes the use of violence as a tool for the establishment of political power in the municipalities of Baixada Fluminense. For that, we analyzed from the period of the territorial formation process of the region to it's current territorial configuration. This analysis led to the understanding that, at first, the violence practiced in the region was directly related to land and commercial issues. In a second period, it began to be used as an element of coercion by the military regime repression apparatus and later, in the period of redemocratization, violence was used at the same time as a "promise and threat" to leverage the entry of political agents into the executive and legislative powers of the Baixadian municipalities. Keywords: Particulate Matter, Geomorphologic Units, Satellite Images, Compass, Environmental Risk.

Keywords: Baixada Fluminense; violence; politics.

\section{LA PROMESA Y LA AMENAZA: EL FUNCIONAMIENTO DE LA VIOLENCIA COMO HERRAMIENTA POLÍTICA EN LA BAIXADA FLUMINENSE}

Resumen: Este artículo analiza el uso de la violencia como herramienta para la instauración del poder político en los municipios de Baixada Fluminense. Para ello, analizamos desde el período del proceso de formación territorial de la región hasta su configuración territorial actual. Este análisis llevó a entender que, en un principio, la violencia que se practicaba en la región estaba directamente relacionada con cuestiones territoriales y comerciales. En un segundo período, comenzó a ser utilizado como elemento de coerción por parte del aparato represivo del régimen militar y, posteriormente, en el período de redemocratización, la violencia se utilizó al mismo tiempo como una "promesa y amenaza" para apalancar el ingreso de agentes políticos en poderes ejecutivo y legislativo de los municipios baixadianos.

Palabras-llave: Baixada FLuminense; violencia; política. 
Introdução

"Depois a gente acerta na Baixada", advertiu o prefeito de Japeri, Carlos Moraes ${ }^{1}$, em julho de 2018, no momento de sua apreensão pela Polícia Civil sob acusação de envolvimento com o tráfico de drogas no município por ele comandado. Moraes, após ameaçar o jornalista da TV Globo que cobria sua prisão, disse que também se sentiu ameaçado e afirmou que depois resolveria a questão na Baixada Fluminense. A ameaça reforça o caráter de que a região é um território no qual a alfabetização das leis é ditada pelos poderosos locais. É dessa forma que a Baixada seria o melhor "fórum" para sanar a contenda entre o prefeito e o repórter.

Se a escolha espacial do político pela Baixada Fluminense denuncia um fórum "privilegiado", a acusação pela qual ele responde enfatiza uma das formas de poder político na região: o uso da violência como método para manutenção do poder. Desse modo, a partir de revisão de literatura e pesquisas em periódicos, almejamos investigar como a coerção física historicamente é transmutada em poder político na região que fabrica suas próprias leis, desde os coronéis do início do século XX até os políticos de 2020 .

Para tanto, o artigo foi dividido em três partes. A primeira parte se dedicou a analisar o processo de

1 Primeiro prefeito do município emancipado em 1991 e ocupante pelo terceiro mandato do executivo municipal pelo partido Progressista em 2016. ocupação territorial da Baixada Fluminense considerando sua imbricada relação socioeconômica com a cidade do Rio de Janeiro. Na segunda, estabelecemos uma análise temporal sobre o uso da violência como gramática usual para solucionar contendas na região. Por fim, a terceira seção trouxe reflexões e casos empíricos de agentes públicos ligados a elementos coercitivos que acessaram cargos eletivos em municípios baixadianos no último pleito municipal.

\section{0 adensamento populacional da Baixada Fluminense a} partir dos loteamentos

A possibilidade de distintas delimitações para o espaço baixadiano tendo como referências aspectos naturais ou socioeconômicos conduziu a delimitações territoriais nem sempre consensuais. Hodiernamente, a concepção de Baixada Fluminense extrapola a acepção meramente geomorfológica, de modo que "o aspecto natural passou a ser associado com os elementos políticos, sociais e econômicos, apresentando construções distintas" (OLIVEIRA, 2004, p. 24).

Todavia, independentemente da composição municipal atribuída à Baixada Fluminense, esta região é subjetivamente construída a partir da violência. 0 órgão do governo estadual responsável pelo combate a esse fenômeno social - o Instituto de Segurança Pública considera a Baixada Fluminense como o agrupamento

Figura 1 - Municípios componentes da Baixada Fluminense.

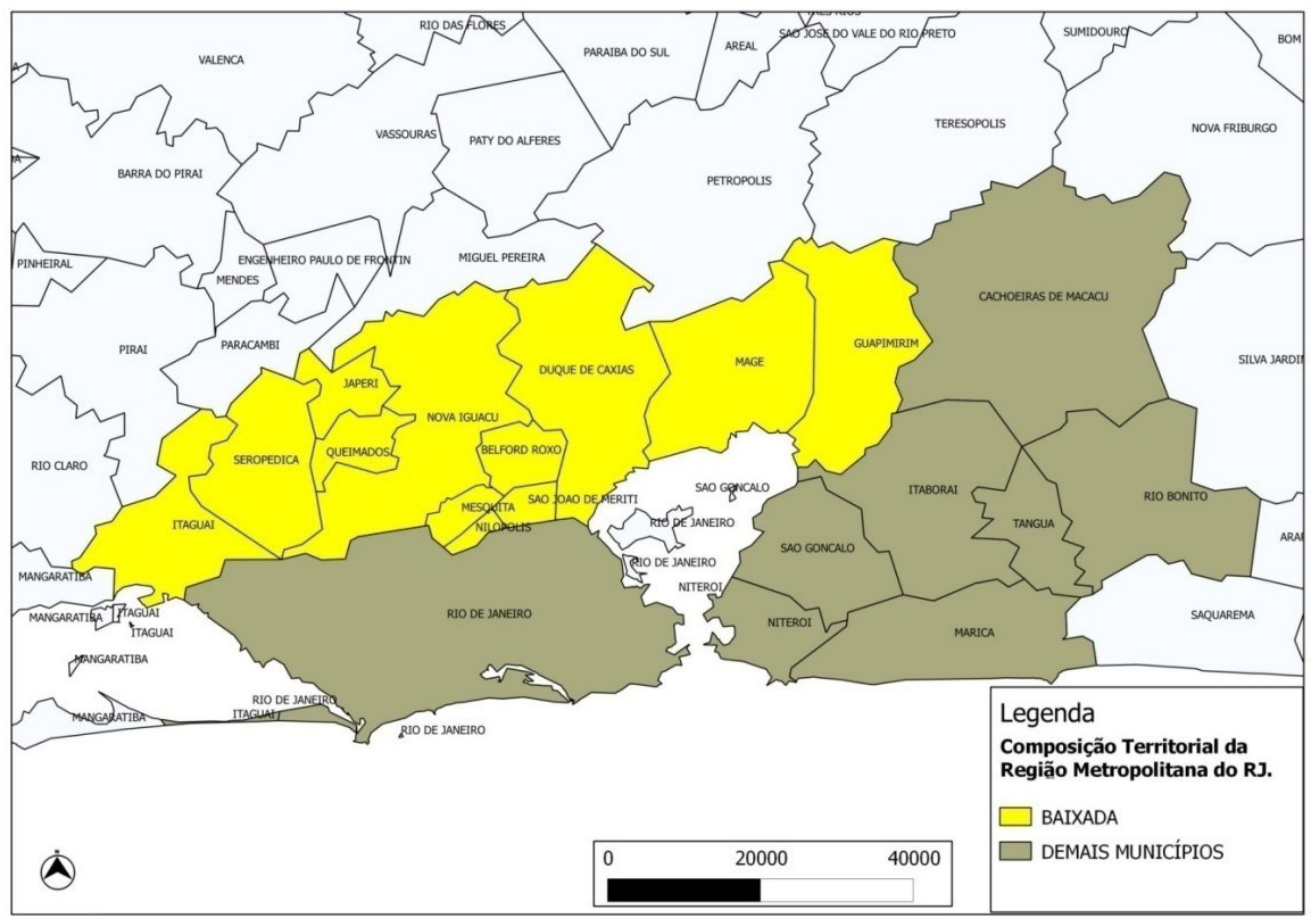

Fonte: ROCHA (2009) 
de 13 municípios (Figura 1).

Em razão da proximidade geográfica com o município do Rio de Janeiro, a dinâmica demográfica e econômica dos municípios do chamado recôncavo da Guanabara ou baixada da Guanabara sempre esteve atrelada à capital. Nesse sentido, a intensificação da ocupação populacional da região se deveu a políticas públicas que visavam atender, em um primeiro momento, as demandas do núcleo metropolitano que se formava. Embora esta relação remonte à época colonial, quando a interação espacial entre o que hoje se denomina Baixada Fluminense e a cidade do Rio de Janeiro se estabelecia pelo fato de o primeiro espaço servir de área portuária, tal processo passou a ser acentuado com o fim do Império.

No início do governo republicano no Brasil, um considerável ponto de inflexão para o desenvolvimento social da Baixada Fluminense ocorreu durante a gestão federal de Nilo Peçanha (1909 a 1910). Apostando na "vocação agrícola" da Baixada Fluminense, Nilo Peçanha, que assumiu a presidência da República com a morte do presidente eleito Afonso Pena, instituiu a Primeira Comissão Federal de Saneamento para a Baixada Fluminense em 1910. Essa Comissão almejava sanar as constantes inundações que a região sofria. Contudo, de acordo com Souto (2016, p. 61), essas intervenções não se limitaram às questões de saneamento - para a autora, "o objetivo da Comissão era desapropriar, sanear, repartir em pequenas propriedades e vender os terrenos. Desta forma o retorno seria praticamente imediato ao fim das obras".

A intenção de ocupação populacional do espaço baixadiano por meio da Comissão de Saneamento é reforçada por Alberto Lamego, o qual entendia que tal intervenção objetivava criar infraestrutura capaz de absorver a futura demanda habitacional da área. Para esse autor, este seria "o verdadeiro fim do saneamento dessas margens paludosas, caso particular em que o desenvolvimento de uma economia agrícola e industrial a ser planejada pelo Departamento, irá sendo recoberto por faixas urbanas satélites do Rio de Janeiro" (LAMEGO, 1964, p. 276). Assim, Geiger e Santos (1955, p. 17) assinalam que "as terras saneadas pelo governo na Baixada, com o objetivo de melhorar as condições da lavoura de abastecimento da capital, foram muito valorizadas pela possibilidade de também serem loteadas". Com efeito, para Segadas Soares (1962, p. 173), a política de saneamento na Baixada Fluminense colocou "à disposição dos capitais da metrópole vizinha, grandes unidades fundiárias que facilitavam certos tipos de empreendimentos, dentre eles os loteamentos. As necessidades de moradia de uma população, que crescia rapidamente".

Em paralelo a esse processo, a prefeitura do Rio de Janeiro passou a elaborar medidas mais restritivas à ocupação do solo, além de aumentar a repressão às favelas. Desse modo, a partir da década de 1930, houve

Tabela 1 - Evolução dos números de lotes e loteamentos na Baixada Fluminense (1929 - 1969).

\begin{tabular}{|c|c|c|}
\hline \multirow{2}{*}{ Período } & \multicolumn{2}{|c|}{ Números absolutos } \\
\hline & Lotes & Loteamentos \\
\hline Até 1929 & 20.524 & 21 \\
\hline $1930-1939$ & 15.419 & 22 \\
\hline $1940-1949$ & 73.025 & 447 \\
\hline $1950-1959$ & 273.208 & 1.168 \\
\hline $1960-1969$ & 120.158 & 615 \\
\hline
\end{tabular}

Fonte: Elaborado pelo autor, 2020, a partir de ALVES (2003, p. 64).

a intensificação do loteamento de terras na Baixada Fluminense, conforme registra a tabela 1.

Em 1952, um grupo de empresários criou a Agrinco do Brasil S.A, companhia que se dizia preocupada com o êxodo rural "para os grandes centros urbanos que resulta não apenas em um abandono por parte do lavrador de suas funções, como principalmente pelo desaparecimento de capital nas zonas de produção agrícola" (O GLOBO, 1952, p. 7). Ainda de acordo com a reportagem, a empresa já havia adquirido propriedades na Baixada Fluminense para o plantio de "laranjeiras, abacateiros, sapotizeiros, aipim e batata". 0 arquétipo da Baixada Fluminense como área rural está expresso no título da citada reportagem: "Valorização e aproveitamento do campo para a salvação das cidades!". Assim, apesar da década de 1950 registrar o maior incremento em número de lotes e loteamentos, o uso agrícola da região ainda persistia.

Todavia, em decorrência da eclosão da Segunda 
Guerra Mundial, a atividade agrícola, notadamente a citricultura, passou por uma crise. Frente a esse quadro, a solução encontrada por partes dos proprietários de fazenda foi fracionar as terras para loteamentos. Nesse período, a autoconstrução, à revelia de uma correspondência infraestrutural por parte do Estado, foi o padrão de construção urbana na Baixada Fluminense e, desse modo, de acordo com a Fundrem (1979, p. 27), "em nenhum momento do processo de ocupação da Baixada pôde-se verificar um comportamento saudável do mercado imobiliário".

A infraestrutura fornecida pelo Estado e a criação de ligação ferroviária com a capital possibilitaram a incorporação de parte da região à mancha urbana da cidade do Rio de Janeiro e influíram no preço dos loteamentos. Nesse momento, de acordo com Pacheco (1984, p. 17), o capital imobiliário

favoreceu o crescimento descontínuo do espaço metropolitano, na medida em que reservou terrenos mais próximos às áreas centrais com o intuito de esperar sua valorização, ao passo que áreas longínquas, além dos limites do então Distrito Federal, foram oferecidas à população de baixa renda, sem a necessária infraestrutura urbana. É desse modo que desponta e se institucionaliza a periferia como habitat dessas populações pobres: atendendo aos interesses imobiliários.

Em razão do quadro mencionado pela autora, a Baixada Fluminense foi destinada à população de menor poder aquisitivo. Essa política, empreendida pelos proprietários fundiários e pelos promotores imobiliários com o consentimento do Estado, expulsou o trabalhador das áreas mais próximas ao núcleo metropolitano. Entretanto, o afastamento físico não impossibilitou a absorção da mão-de-obra para as atividades localizadas na área central. Por essa lógica geográfica, o capital fundiário se beneficiou com a venda dos terrenos periféricos da Baixada Fluminense e o capital industrial manteve o trabalhador relativamente próximo ao local de trabalho.

O loteamento do território baixadiano se favoreceu ainda de outras intervenções infraestruturais promovidas pelo Estado. Entre elas, Alves (2003, p. 63) destaca

a eletrificação da Estrada de Ferro Central do Brasil, a partir de 1935; a tarifa ferroviária única no Grande Rio; a construção da avenida Brasil, em 1946; a criação do Serviço de Malárias da Baixada Fluminense, em 1947; e a abertura da rodovia Presidente Dutra, em 1951.

O capital privado, em decorrência do surto industrial pelo qual passou a Baixada Fluminense a partir da década de 1950, também atuou para o processo de adensamento populacional da região. Desse período datam a instalação da indústria farmacêutica Bayer em Belford Roxo e da Fábrica Nacional de Motores e da Reduc, ambas em Duque de Caxias (ROCHA, 2009).

Assim sendo, os municípios da Baixada Fluminense tiveram seu processo de ocupação populacional atrelada à expansão fundiária do então Distrito Federal e sua dinâmica econômica, mesmo após a transferência da capital do país para Brasília em 1960, e posterior criação da Região Metropolitana do Rio de Janeiro (RMRJ), continuou vinculada à cidade do Rio de Janeiro. Em virtude dessas condições, a região expressa de forma cristalina sua condição periférica no bojo da RMRJ. Sobre essa relação, Corrêa (2011, p. 160-161) entende que "a periferia da metrópole é o lugar de existência e reprodução de parcela ponderável das camadas populares. No caso da metrópole carioca, esta periferia é conhecida, sobretudo como a Baixada Fluminense", a qual, por sua vez, consiste na "justaposição de numerosos loteamentos, que acabam formando um mosaico irregular, cujo conteúdo em termos de equipamentos de consumo coletivo é extremamente precário".

Com efeito, "mais que um substantivo próprio que possui a função de nomear; atribui-se à 'Baixada' uma ideia 'qualificadora', quase que adjetivada, associada às noções de miséria, fome, violência, grupos de extermínio, periferia, lugar distante etc. (ROCHA, 2013, p. 145). Entre as "qualificadoras" da Baixada Fluminense aludidas por Rocha, a seção seguinte discute a violência, a qual consiste em um conceito central para esse artigo e para as relações de poder estabelecidas no espaço por ele analisado.

A história da violência na Baixada: dos "coronéis" do século $\mathrm{XX}$ aos políticos do século $\mathrm{XXI}$

Certamente o poder público não inventou a violência na Baixada Fluminense. Sua produção inicialmente esteve a cargo de "coronéis" civis e não militares. Porém, não ter reprimido de maneira eficaz esses agentes serviu para o seu fortalecimento. Arendt (2016, p. 23) considera ser "surpreendente que a violência tenha sido raramente escolhida como objeto de consideração especial". Por essa razão, analisaremos a violência almejando compreender como ela edificou um território do medo no recorte em tela.

Para Stoppino (1998, p. 1291), violência corresponde a qualquer

intervenção física de um indivíduo ou grupo contra outro indivíduo ou grupo (ou também contra si mesmo). Para que haja Violência é preciso que a intervenção física seja voluntária: o motorista implicado num acidente de trânsito não exerce a Violência contra as pes- 
soas que ficaram feridas, enquanto exerce Violência quem atropela intencionalmente uma pessoa odiada. Além disso, a intervenção física, na qual a Violência consiste, tem por finalidade destruir, ofender e coagir.

0 autor traz duas importantes condições para delimitar a violência enquanto tal: intencionalidade e coação. Estas condições possibilitam que a violência tenha um caráter instrumental. Conforme expresso na citação acima, uma intervenção física acidental não tem como objetivo forçar o indivíduo agredido a adotar o comportamento pretendido pelo agressor. Pelo contrário, a natureza acidental do ato pode impor uma circunstância na qual o agredido passe a determinar 0 comportamento do agressor. No exemplo utilizado por Stoppino, o atropelador, temendo o agravamento das condições físicas do atropelado, talvez fique à mercê das imposições do primeiro. Nesse exemplo específico, é questionável se o acidentado dispõe de algum poder sobre o agressor, contudo, caso o acidente tenha sido intencional, a violência em questão objetivava a coação e, nesse caso, o agredido não impõe nenhuma regra ao agressor.

Destacando o impacto sobre os indivíduos para conceituar a violência, Zaluar $(1999$, p. 8) observa que ela se nota quando se ultrapassa

um limite ou perturba acordos tácitos e regras que ordenam relações, adquirindo carga negativa ou maléfica. É, portanto, a percepção do limite e da perturbação (e do sofrimento que provoca) que vai caracterizar um ato como violento, percepção esta que varia cultural e historicamente.

Ainda centrada sobre os sujeitos passivos da ação, Odalia (1991) aproxima a violência à noção de privação. Do mesmo modo que a privação aparece imbricada à violência, esse último vocábulo suscita uma aproximação à noção de crime. Assim, para Oliveira (2016, p. 27), "violência e crime possuem um conjunto de interseção, mas não são em si sinônimos. Nem todas as formas de violência são caracterizadas como crime, tampouco todos os crimes são necessariamente violentos ou considerados socialmente violentos". Melgaço (2010), por exemplo, alude sobre algumas formas de violência não criminalizadas como a categoria marxista da mais-valia, a violência do Estado apontada por Lênin, a violência legítima desse ente referida por Weber, além de violências "silenciosas" como o racismo, a homofobia, a xenofobia ou o machismo.

Essas formas de violência, embora sejam encontradas no recorte espacial analisado neste artigo, não respondem diretamente como componente crucial para a formação de uma territorialidade do medo. Dessa forma, entenderemos como violência estruturante para o território baixadiano uma ação voluntária impetrada sobre um indivíduo ou grupo de indivíduos visando uma sanção de ordem física ou psíquica - medo, sofrimento, dor -, a qual tem por finalidade última impor certo comportamento ao(s) agredido(s) que o(s) impeça(m) de discordar do agressor.

A Baixada Fluminense não possui exclusividade no tocante à existência da violência, outras periferias nacionais padecem do mesmo mal. Ainda que notadamente consista em um fenômeno urbano e metropolitano, a violência "se estende do centro à periferia da cidade e seus longos braços a tudo e a todos envolvem, criando o que se poderia chamar ironicamente de uma democracia da violência" (ODALIA, 1991, p. 9-10).

Embora a violência encontre-se presente em diferentes escalas, suas implicações são distintas quando considerados os espaços nos quais ela se manifesta. Quando praticada em áreas nobres, ela tem estreita ligação com atentados contra a propriedade - assaltos a residências, roubos de carros e objetos pessoais de alto valor. Já em áreas periféricas, somamse a essas formas de violência as praticadas contra a integridade física, como os homicídios. Assim, enquanto o crime relacionado à propriedade que ocorre em áreas nobres, em regra, não objetiva a dominação territorial daquele espaço, a violência em áreas periféricas permite a transmutação de um ato imposto à integridade física e mental de alguém em um projeto de poder político sobre aquele espaço.

0 processo de transmutar violência em poder político em nosso recorte espacial passou a ser observado com maior nitidez a partir do início do século $X X$, aprimorandose a partir da segunda metade desse período. Para o entendimento desse fenômeno, Alves (2003) traça seu panorama cronológico da violência e sua natureza na referida região. Nossas reflexões referentes às articulações entre a violência e o poder político na Baixada Fluminense seguirá a divisão estabelecida por esse autor.

Para Alves (1994, p. 10), em um primeiro momento, a violência

esteve associada à atuação das milícias vinculadas às empresas e grupos loteadores que retalhavam as terras de acordo com a resistência dos ocupantes anteriores. Estes, por sua vez, respondiam, em casos extremos, de forma armada, iniciando os conflitos que transformaram a Baixada numa área conflagrada. Neste mesmo período, os caciques do poder local passaram a recorrer à truculência, herdada do coronelismo rural, na solução da crise hegemônica originada na recomposição da economia em bases urbanas. 
Ao analisar o primeiro período de conflagração da violência em território baixadiano, Alves identifica no processo de adensamento populacional da Baixada Fluminense a manifestação inicial de uma violência mais ostensiva, a qual guardava efetiva ligação com o coronelismo rural. Por essa conjuntura sociopolítica, relações sociais comuns em áreas rurais do século XIX, como o coronelismo, ainda encontravam ecos no início do adensamento populacional da Baixada Fluminense no século seguinte.

Para Leal (1997, p. 40), o coronelismo "é antes uma forma peculiar de manifestação do poder privado, ou seja, uma adaptação em virtude da qual os resíduos do nosso antigo e exorbitante poder privado têm conseguido coexistir com um regime político de extensa base representativa". Embora Leal (1997) considere as raízes históricas do coronelismo ancoradas no ruralismo, o autor menciona sua capacidade de perdurar no tempo e se amplificar no espaço. Nascido em um Brasil agrário e rural, a forma de mandonismo oriunda do coronelismo permaneceu ativa na transição nacional para um modelo urbano-industrial, continuando influente mesmo após a expansão do sufrágio universal. Por essa razão, Beloch (1986) lança mão da expressão "coronelismo urbano", a qual, em nosso recorte espacial, pode ser atribuída atualmente a figuras ligadas à contravenção (jogo do bicho), às milícias ou ao tráfico de drogas, pois, de acordo com Leal (1997, p. 42), o "coronel" exerce

uma ampla jurisdição sobre seus dependentes, compondo rixas e desavenças e proferindo, às vezes, verdadeiros arbitramentos, que os interessados respeitam. Também se enfeixam em suas mãos, com ou sem caráter oficial, extensas funções policiais, de que frequentemente se desincumbe com a sua pura ascendência social, mas que eventualmente pode tornar efetivas com o auxílio de empregados, agregados ou capangas.

O domínio territorial construído por esses agentes, por extensão, conferiu-lhes uma autoridade extraoficial sobre esse espaço. À revelia das forças de segurança oficiais, ou a partir de seu consentimento, os "coronéis" da Baixada Fluminense foram paulatinamente elaborando as leis, proferindo as sentenças e promovendo as execuções - das sentenças e dos sentenciados.

As tensões geradas por esse processo resultaram em transformações significativas para esse recorte espacial. Em um cenário de instabilidade quanto aos limites da propriedade fundiária, a violência passou a funcionar como um mecanismo efetivo para demarcação dessas "fronteiras" privadas. A associação da Baixada Fluminense com a violência nasceu dessa tensão gerada entre os "posseiros" e aqueles que se autodenominavam proprietários das terras. Como consequência, ao passo em que ditava a lógica fundiária, a coerção física também inaugurava um território do medo na Baixada Fluminense.

Posterior a esse movimento e aliada às políticas públicas de segurança ineficientes, a violência na Baixada Fluminense conheceu outro patamar de sofisticação. Esse novo arranjo promoveu a "modernização" da máquina de coerção, inaugurando o segundo momento de conflagração da violência no espaço baixadiano. De acordo com Alves (1994, p. 10),

transposta esta primeira fase de ocupação das suas terras e rearranjo do poder político, a Baixada conhecerá o período que a elevou à categoria de "região mais violenta do mundo". Os aparatos para oficiais e oficiais de extermínio passam a "desovar" os "ovos" gerados no processo de retração do capital e de crise econômica somado à formação de centros-periferias e, consequentemente, da guerra de classe dentro das sub-regiões da Baixada. A violência do extermínio foi assim convocada para garantir a manutenção dos interesses econômicos e políticos dos que tinham na Baixada seus grandes negócios.

O cenário apontado pelo autor ajudou na consolidação dos grupos paramilitares. Alves $(2015$, p. 7$)$ sintetiza a natureza desses grupos de extermínio e sua forma de atuação no decorrer do século XX. Para ele, a articulação que permitiu a ascensão desses grupos foi construída no período do golpe civil-militar de 1964 "a partir da articulação de três elementos: 1) o aparato policial que compõe os grupos e que assassina; 2) o financiamento por grupos econômicos; e 3) o suporte de políticos que garantem o funcionamento do grupo e se valem dos seus serviços".

Essa conjuntura indica a manifestação de formas de violência mais eficientes e melhores estruturadas em razão de seu conluio com o aparelho estatal. A "mão de obra" para execução dos crimes passa a ser de agentes do Estado, como policiais financiados por agentes econômicos e salvaguardados por agentes políticos. Essa associação produziu a disseminação da atuação de grupos paramilitares, os chamados grupos de extermínio - os quais consistem em um "sistema de justiça privada" (ALVES, 2003, p. 21), conhecidos popularmente como esquadrões da morte e polícia "mineira", em razão de agir de maneira silenciosa e discreta, como agiriam os naturais desse estado, de acordo com a crença popular. Esses grupos paramilitares foram os responsáveis por grifar na Baixada Fluminense a alcunha de "região mais violenta do mundo". Esse processo de degradação social aconteceu em consonância ao período mais repressor da história recente do país, o regime ditatorial militar.

O golpe militar de 1964 impôs alterações consideráveis na estrutura sociopolítica fluminense. Quatro anos antes 
da instauração do regime militar, o então estado da Guanabara deixou de ser a capital federal, entretanto, por sediar as maiores estatais da união e o comando geral do exército brasileiro, a antiga capital federal ainda conservava sua importância geopolítica. Devido à proximidade geográfica da Baixada Fluminense em relação ao estado da Guanabara, a região passou a compor a chamada "área de interesse". Em razão dessa condição, a ditadura militar passou a atuar no jogo político da Baixada Fluminense, minando quadros que se estabeleceram em momento anterior à sua instalação ou aqueles que atuavam à revelia de seus interesses. Com efeito, as forças políticas que não se alinharam aos novos ditames pós-1964 foram alijadas do processo eleitoral. 0 apoio ou a restrição dos militares não estavam relacionados ao modus operandi dos políticos, mas tão somente ao seu alinhamento ideológico em relação ao regime. Desse modo, grupos políticos que se utilizavam amplamente de métodos coercitivos para constituir seus territórios, tiveram tratamentos distintos durante o regime de exceção. A ditadura militar passou a perseguir figuras como Getúlio de Moura (Nova Iguaçu) e Tenório Cavalcanti (Duque de Caxias), ao mesmo tempo em que favoreceu a ascensão da família Abraão-Sessim em Nilópolis, ligada à contravenção.

A ditadura militar inaugurou, assim, um novo momento no tocante à prática da coerção física na Baixada Fluminense. Se a disputa fundiária marcou a primeira fase cronológica da violência como força política, a questão ideológica, juntamente com outras disputas territoriais de variadas ordens, permeou a segunda fase. Ancorados no lema "bandido bom ébandido morto", nesse período histórico, os grupos de extermínio torturavam e matavam pessoas que cometiam delitos como roubos. Ancorado no lema "Brasil: ame-o ou deixe-o", os militares torturavam e matavam pessoas que cometiam o delito de discordar do regime. 0 diferencial entre essas duas formas de sanções físicas é que a primeira era executada por agentes públicos de segurança de forma ilegal mas, em maior ou menor grau, com o consentimento do Estado -, já a segunda era operada diretamente pelo Estado.

Apesar dessas articulações, os esquadrões da morte não podem ser considerados filhos diretos do regime militar. Os grupos de extermínio têm relação mais direta com a configuração socioeconômica da Baixada Fluminense daquele momento histórico do que propriamente com o regime político em vigor. A atuação desses grupos já estava em curso antes do início do regime de exceção. Sua criação ocorreu

na Guanabara em 1958, no antigo Serviços de Di- ligências Especiais, [com] uma equipe de policiais que se identificavam com as iniciais EM. Os componentes de tal grupo atestam hoje que as iniciais eram Esquadrão Motorizado. Mas o certo é que desde que surgiu passou a ser conhecido Esquadrão da Morte, embora negue as mortes que Ihe são atribuídas (O GLOBO, 1969, p. 17).

Embora anterior ao regime de exceção, a partir da ditadura agentes ligados a grupos paramilitares passaram a manter estreitas ligações com líderes do regime militar. Essas relações aumentavam as garantias de impunidade. Por esse motivo, a Baixada Fluminense, na década de 1970, presenciou taxas de homicídios elevadas. 0 delegado de Nova Iguaçu nesse período, Luís Gonzaga de Lima Costa, afirmou que "num só ano (69/70), o Esquadrão da Morte despejou em Belford Roxo mais cadáveres que o número registrado em toda a Chicago na época da Lei Seca: 165 mortos em Belford Roxo contra 162 em Chicago" (O GLOBO, 1972, p.32).

Quando o "absurdo perdia a modéstia", o regime militar intervinha a fim de manter um aparente distanciamento com os grupos de extermínio da Baixada Fluminense. Em 1974, quando dois menores de idade foram mortos com 64 tiros, o presidente militar Geisel, por meio do ministro de justiça Armando Falcão, solicitou à secretaria estadual de segurança a rápida solução para o caso. A pressão resultou na prisão do subdelegado de Nova Iguaçu, o qual, de acordo com testemunhas, foi até o local do duplo assassinato e "teria recolhido os documentos das vítimas para dificultar tanto a identificação como o esclarecimento do homicídio" (O GLOBO, 1974, p. 7). Os dois soldados da polícia militar, executores da ação e réus confessos, foram inocentados quatro anos após o crime: "o conselho de sentença entendeu que os PMs 'agiram no estrito cumprimento do dever legal"' (PEREIRA, 1981, p. 33).

Apesar dessa proteção, esses esquadrões da morte passaram a operar uma alteração no final da década de 1970. Neste ano, o então diretor do Departamento Geral da Polícia Civil, delegado Mário Cesar da Silva, revelou o "reaparecimento do Esquadrão da Morte na Baixada Fluminense", mas esclareceu: "não o de antigamente, mas um Esquadrão privado, o que vocês da Imprensa chamam de polícia mineira" (O GLOBO, 1977, p. 13). Sete meses depois, o secretário de segurança pública, Brum Negreiros reafirmou em entrevista que em sua opinião e na dos jornalistas presentes, "o Esquadrão da Morte está todo no xadrez" (O GLOBO, 1978, p. 15). A declaração revela desconhecimento da estrutura criminal desses grupos ou acobertamento da parte dos órgãos responsáveis à sua repressão.

Mais de 11 anos após a declaração do secretário de segurança, a Diocese de Duque de Caxias elaborou um 
relatório sobre a violência na Baixada Fluminense. O documento foi divulgado em 24 de novembro de 1989 , pela rede televisiva britânica $\mathrm{BBC}$. De acordo com a emissora,

os Esquadrões da Morte assassinaram mil menores nos primeiros seis meses deste ano. [...] esses Esquadrões são formados com dinheiro de comerciantes das ruas em que dormem e mendigam essas crianças abandonadas por suas famílias. Os comerciantes pagam os assassinatos". (O GLOBO, 1989, p. 14)

Ainda no início da década de 1980, os grupos de extermínio eram compostos, também, por agentes não vinculados ao aparato estatal de segurança. Apesar da vitalidade desse território coercitivo na Baixada Fluminense, a execução de um projeto de poder por meio da violência sofreu nova alteração a partir dessa década por meio desse novo perfil de agentes. Para Alves (2005, p. 24), esse processo se deveu à

inovação no funcionamento deste aparato de execuções sumárias. Sofrendo com a maior exposição e cobrança da mídia, numa conjuntura de abertura política, os grupos de extermínio iniciaram um processo de autonomização frente ao aparelho policial. Progressivamente, policiais militares e civis se transformaram em agenciadores dos serviços destes grupos, mantendo o envolvimento, mas lidando agora com um mercado mais competitivo, onde vários outros grupos atuavam.

Em paralelo a esse movimento aludido por Alves, o enfraquecimento do regime militar frente às demandas democráticas alterou a relação entre os agentes responsáveis pela violência e sua proximidade ao aparelho estatal. Temendo o fim da impunidade dos crimes acobertados antes pelos militares, os policiais que atuavam nos grupos de extermínio mantiveram sua atuação, porém de maneira menos ostensiva e passaram a buscar apoio em membros da sociedade civil. Tal movimento pode ser entendido como precursor das chamadas milícias, as quais dominam partes da zona oeste da cidade do Rio de Janeiro e da Baixada Fluminense no período atual.

Com o fim do regime militar, os anos de 1990 presenciaram uma queda nas taxas de homicídio. Para Alves (2005, p. 25), "a redução dos homicídios estava diretamente associada à sua capacidade de interferir na nomeação de delegados, destituindo aqueles vinculados ao esquema de execuções, que por sua vez agiam associados ao poder político local". Com o fim da interferência no comando da polícia civil, a impunidade diminui, forçando a modificação do modus operandi desses esquadrões da morte. Se não havia mais a possibilidade da proteção dos militares como existia na ditadura, a saída para esses grupos seria, mais uma vez, retornar ao aparelho do Estado, dessa vez de forma "democrática". Por esse mecanismo, "a Baixada assistiu à chegada dos matadores ao poder na justificativa totalitária do bandido bom é bandido morto. A deterioração da segurança pavimentava o sucesso eleitoral dos que a partir do voto lavavam sua cidadania nas urnas" (ALVES, 2015, p. 8).

Assim, emerge a terceira fase da violência como ferramenta sociopolítica na região. Na primeira fase, a violência estava amparada em questões latifundiárias e visava uma ampliação da propriedade e, no limite, impunha um território. A segunda fase marca um momento no qual a violência se dissemina como uma manifestação político-territorial mais clara. Tortura e execuções de bandidos e comunistas demarcaram a Baixada Fluminense como território de grupos paramilitares apoiadas pelo regime de exceção. $\mathrm{Na}$ terceira fase, a qual compreende o período atual, os agentes executores da violência sofisticam sua atuação e passam a compor diretamente os poderes legislativo e executivo, seja de forma direta ou por intermédio de pessoas ligadas aos seus interesses. Com efeito, na Baixada Fluminense ocorreu a "politização" da violência, de modo que os mecanismos de repressão foram convertidos em instrumentos políticos.

Ambicionamos salientar neste artigo como a intervenção física sobre alguns indivíduos torna-se capaz de permitir a sujeição política de uma ampla camada da sociedade e, por esse instrumento, produz um território. Ou seja, analisamos a dimensão político-partidária permitida com base no exercício da violência. Por essa razão, os grupos de extermínio ganham relevância a partir do momento em que produzem quadros partidários. Sobre os desdobramentos sociopolíticos desse processo, se debruça a parte seguinte desse artigo.

\section{A violência como ferramenta para a conformação política da Baixada Fluminense}

Para fins de gestão do espaço fluminense, o ISP (Instituto de Segurança Pública) regionaliza o estado em 4 grandes regiões. Cabe ressaltar que a Baixada Fluminense não existe oficialmente enquanto Região Administrativa de governo. Contudo, quando a Secretaria de Segurança Pública a institui como uma região, tal fato assinala que sua existência só ganha contornos de "realidade" se entendida a partir das atrocidades criminais que vitimizam seus moradores. Desse modo, a violência oficializa esta região para os órgãos governamentais.

Todavia, embora para a Secretaria de Segurança Pública o entendimento de Baixada Fluminense passe, 
inequivocamente pela questão da violência, as políticas públicas ofertadas a essa sub-região metropolitana expõe uma distinção estratégica clara quando comparada ao núcleo metropolitano. Essa diferença se reflete na geografia das UPPs (Unidades de Polícia Pacificadora) e na distribuição de agentes de segurança entre os batalhões da RMRJ. Em 2018, das 37 favelas que contavam com a instalação de Unidades de Polícia
Pacificadora, 36 estavam situadas nos limites da cidade do Rio de Janeiro e apenas uma estava instalada em um município da Baixada Fluminense, a UPP do Complexo da Mangueirinha, em Duque de Caxias. Em relação ao efetivo policial, enquanto na capital havia um policial para cada 800 residentes em 2018, e nos demais municípios metropolitanos um para cada 883 , a Baixada Fluminense

Tabela 10 - Relação entre o número de policiais militares e habitantes entre os municípios da RMRJ (2018)

\begin{tabular}{c|c|c|c|}
\hline Municípios & $\begin{array}{c}\text { Número de } \\
\text { policiais }\end{array}$ & $\begin{array}{c}\text { População } \\
\text { atendida }\end{array}$ & $\begin{array}{c}\text { Habitantes } \\
\text { por policial }\end{array}$ \\
\hline Belford Roxo & 349 & 495.783 & $1.420,58$ \\
Duque de Caxias & 813 & 890.997 & $1.095,93$ \\
Magé e Guapimirim & 359 & 295.341 & 882,67 \\
Niterói e Maricá & 978 & 652.036 & 666,70 \\
Mesquita, Nova Iguaçu e Nilópolis & 899 & 1.128 .255 & $1.255,01$ \\
São Gonçalo & 929 & 1.049 .826 & $1.130,06$ \\
São João de Meriti & 440 & 460.461 & $1.046,50$ \\
Seropédica, Itaguaí, Paracambi, Queimados e Japeri & 475 & 503.855 & $1.060,74$ \\
Cachoeiras de Macacu, Tanguá, Rio Bonito e Itaboraí & 451 & 380.684 & 844,08 \\
\hline Baixada Fluminense & 3.335 & 3.774 .692 & $1.131,84$ \\
Demais municípios da RMRJ & 2.358 & 2.082 .546 & 883,18 \\
Rio de Janeiro & 8.151 & 6.520 .266 & 799,93 \\
\hline
\end{tabular}

Fonte: Elaborado pelo autor a partir de dados coletados em pesquisa de campo.

contava com um policial para cada 1.131 moradores, conforme aponta a tabela 2 .

0 descaso estatal no tocante às políticas públicas referentes à segurança favorece que a violência seja utilizada como barganha política por agentes públicos com atuação na Baixada Fluminense. Em um processo "desigual e combinado", a violência, ao mesmo tempo em que possibilita a ascensão política de agentes que a utilizam como instrumento de domínio territorial, também é um dado considerável para a construção de projetos políticos que dizem visar o seu combate, pois, nessa conjuntura, "assim como o dinheiro líquido disponível para investimentos de todo o tipo, o 'capital do medo' pode ser transformado em qualquer tipo de lucro político ou comercial" (BAUMAN, 2009, p. 55).

"O capital do medo", quando colocado a favor da política na Baixada Fluminense, permite, sem constrangimento algum, contradições. Como amplamente sabido, a segurança pública não é uma atribuição dos municípios, entretanto, o pleito municipal de 2016 consagrou projetos políticos de agentes relacionados a grupos paramilitares ligados a execuções sumárias de pessoas e que, por essa condição, eram dubiamente associados ao combate da criminalidade. Tal entendimento se deve ao fato dos homicídios consistirem em um indicador amplamente utilizado para atestar o grau de violência de um lugar, contudo, esse índice apresenta maior validade para os agentes externos do que para a população local. Por esse cálculo ilógico, mais homicídios resultam em menos roubo, logo, em menos violência e, por essa razão, os atos violentos passam a ser associados não mais às sanções físicas e psicológicas impostas a alguém, mas, sobretudo, ao ataque à propriedade privada.

Por essa razão, a prática da violência pode funcionar como atração e repulsa na hora de decidir o voto. A eleição de alguns quadros políticos em 2016 se deveu a sua prática de "coibir a bandidagem". Três prefeitos da Baixada Fluminense eleitos nesse pleito tinham relação com grupos paramilitares, traficantes de drogas ou com a contravenção. Rogério Lisboa, prefeito de Nova Iguaçu, é filho do delegado de polícia aposentado Juarez Lisboa, o qual, na década de 1960 e 1970, tinha ligações com grupos de extermínios e com o jogo do bicho². Farid Abraão, prefeito de Nilópolis, é irmão do patrono da Escola de Samba Beija-Flor, Anízio Abraão, dono dos principais pontos do jogo do bicho na Baixada Fluminense ${ }^{3}$. Já em Japeri, Carlos Moraes foi preso em 2018 sob acusação de associação com o tráfico de drogas e porte ilegal de

2 Disponível em: $\quad$ <https://www1.folha.uol.com.br/fsp/1996/9/12/ cotidiano/18.html>

3 Disponível em: <http://www.ilisp.org/opiniao/me-da-um-bicheiro-ai/> 
armas $^{4}$.

No poder legislativo, a violência também se revela como uma gramática constante no glossário político. Em março de 2018, o ex-policial e vice-presidente da Câmara de Mesquita foi preso por posse ilegal de armas ${ }^{5}$. Na mesma operação que prendeu o prefeito eleito de Japeri, foi decretada a prisão do presidente da Câmara Municipal e de outro vereador pelo mesmo crime. Em maio de 2019, o presidente da Câmara de Vereadores de Nilópolis foi preso, acusado de homicídio e de ter encomendado o assassinado de outro vereador ${ }^{6}$. Em Queimados, em julho do mesmo ano, o presidente da Câmara dos Vereadores foi preso, acusado de chefiar a milícia que atuava na cidade $^{7}$. Em setembro, foram encontradas cinco armas de fogo na casa de um vereador de Duque de Caxias, que tinha ligação com o furto de combustíveis ${ }^{8}$. Um mês depois, o ex-presidente da Câmara Municipal de Belford Roxo foi preso sob acusação de homicídios ${ }^{9}$ e extorsão; no mês seguinte, outro vereador do município foi alvo de operação de combate às milícias ${ }^{10}$.

Os casos acima apontados se limitam a ocorrências policiais relacionadas a políticos eleitos no último pleito municipal e com desvios de conduta relativas a crime envolvendo letalidade, ocorridos nos últimos dois anos apenas. Caso o recorte temporal fosse ampliado, o número de agentes públicos com cargos eletivos na Baixada Fluminense implicados em crime de violência seria superior. Nesse sentido, ao eleger representantes políticos ligados às execuções sumárias, a população entende ter minado uma violência da qual ela pode ser vítima a qualquer momento, como os assaltos, os roubos ou os latrocínios, e reforça uma violência da qual ela só poderá ser vítima nas circunstâncias em que cometer "erros", como são as execuções sumárias. Nesse cenário, o medo funciona como elemento fundamental para a construção política, possibilitando que mecanismos ilegais ganhem aparência de legalidade.

4 Disponível em: <https://g1.globo.com/rj/rio-de-janeiro/noticia/2018/07/27/ prefeito-de-japeri-e-preso-por-suspeita-de-envolvimento-com-o-trafico-de-drogas. ghtml>

5 Disponível em: <https://odia.ig.com.br/rio-de-janeiro/2018/03/5520317-expm-vice-presidente-da-camara-de-mesquita-e-preso.html>

6 Disponível em: <https://g1.globo.com/rj/rio-de-janeiro/noticia/2019/05/10/ policia-procura-suspeitos-de-mandar-matar-vereador-de-nilopolis-rj-presidenteda-camara-esta-preso.ghtml>

7 Disponível em: <https://g1.globo.com/rj/rio-de-janeiro/noticia/2019/07/18/ mprj-e-policia-civil-fazem-operacao-contra-suspeitos-ligados-a-milicia-e-aotrafico-na-baixada-fluminense.ghtml>

8 Disponível em: <https://g1.globo.com/rj/rio-de-janeiro/noticia/2019/09/12/ divisao-de-homicidios-encontra-armas-na-casa-de-vereador-de-duque-de-caxias. ghtml>

9 Disponível em: <https://noticias.r7.com/rio-de-janeiro/ex-presidente-dacamara-dos-vereadores-de-belford-roxo-e-preso-22102019>

10 Disponpivel em: <https://exame.abril.com.br/brasil/operacao-mirapolicias-e-vereador-suspeitos-de-integrar-milicia-no-rio/>
A violência sobre o corpo não apenas mina uma eventual oposição do agredido em relação ao grupo de matadores, ela também aumenta a adesão a esse grupo de pessoas que não querem padecer do mesmo mal e, assim, o terror concorre para a produção de um poder coercitivo. A sanção física "atinge a pessoa moral com uma gravidade equivalente, quando não superior, à intensidade do sofrimento físico provocado. E a atinge assim profundamente por conta da simbiose que instaura, da dinâmica metonímica que aciona" (SOARES, 1996, p. 59). Essa fragilidade moral da qual a pessoa vítima da agressão sofre, também atinge as pessoas que não a sofreram fisicamente. É dessa forma que tal ação contribui para a adesão de mais pessoas aos interesses dos grupos repressores. Entre esses interesses, estão as aspirações políticas. Esta fórmula está no cerne da ascensão política de agentes ligados aos grupos de extermínio na Baixada Fluminense.

A partir dessa visão, cabe aprofundar a distinção entre violência e poder, considerando a realidade baixadiana especificamente. 0 pensamento arendtiano considera que "poder e violência são opostos, onde um domina absolutamente, o outro está ausente" (ARENDT, 2016, p. 73). Dessa feita, pode-se afirmar que o poder e a violência guardam uma dimensão de proporcionalidade entre si. A violência, apesar de sua diferenciação em relação ao poder, conforme salienta Arendt, foi capaz de erigir um território na Baixada Fluminense. Assim, pela perspectiva filosófica, o território baixadiano assentado sobre a violência não expressaria uma manifestação de poder.

Todavia, como "nenhuma teoria pode se desenvolver sem encontrar uma espécie de muro e é preciso a prática para atravessar o muro" (FOUCAULT, 2016, p. 130), o espaço político da Baixada Fluminense consiste em um entrave para a teoria segundo a qual o território só existe na presença de um poder e de que o poder só existe na ausência da violência. A discussão empírica dos territórios baixadianos atravessa e desmorona esse "muro". Assim, neste recorte espacial específico, reafirmamos que o domínio espacial alicerçado na violência consiste em uma manifestação clara e objetiva de poder, pois a coerção física nesse contexto influi decisivamente na capacidade de impor o comportamento de outros, logo, plasma um território.

Entretanto, "a não ser um desequilibrado, ninguém pratica o mal pelo mal: em política, principalmente, recorre-se à violência, quando outros processos são mais morosos, ou ineficazes, para o fim visado" (LEAL, 1997, p. 68). Por essa razão, como um poder ancorado somente sobre a violência se auto desgasta com maior facilidade, novas formas de mantê-lo e ampliá-lo foram 
paulatinamente incorporadas pelos agentes na Baixada Fluminense, começando com o ganho de "legitimidade" ao se infiltrar no aparelho político.

\section{Considerações finais}

Entre as práticas pouco republicanas que permeiam a atividade político-partidária na Baixada Fluminense, a violência possui papel de destaque, estando no cerne do processo de formação da própria região, tanto em termos materiais quanto em termos simbólicos. Em um primeiro momento a violência na Baixada Fluminense apresenta uma conotação ruralista. 0 alcance da violência foi intensificado a partir do adensamento populacional da região e seu processo de incorporação imobiliária à malha urbana da cidade do Rio de Janeiro. Desse modo, as sanções físicas conhecem sua primeira mudança ao passar de uma violência restrita à resolução de impasses interpessoais para ferramenta de imposição fundiária. Em seguida, a partir dos anos 1990, a violência atinge um grau mais elevado de sofisticação ao infiltrar agentes ligados a ela nos legislativos e executivos dos municípios da Baixada Fluminense.

A ascensão política de nomes ligados a grupos paramilitares em municípios baixadianos se deve, em larga medida, ao fato de a coerção física consistir em um instrumento político poderoso na adesão aos projetos políticos desses agentes. Em uma região com elevadas taxas de criminalidade, o discurso do "bandido bom é bandido morto", tem capacidade maior de atrair simpatizantes. A aceitação de parte da população do modus operandi desses grupos de extermínio, embaraça o pensamento e distorce a razão. Esses moradores entendem que a execução sumária seja uma forma de violência menor frente à usurpação de um bem material seu.

O prestígio alcançado no combate à "violência" utilizando-se de uma violência ainda maior, como é a supressão da vida de outra pessoa, permitiu a esses agentes imputarem o "medo" a uma parcela da população e o "respeito" à parcela restante que aprova o modus operandi desses grupos. Sendo pelo medo imposto ou pelo respeito alcançado, as duas acepções favoreceram seus processos políticos no legislativo e no executivo. Esse processo, em alguma medida, encontra exemplos na cidade do Rio de Janeiro. Contudo, em razão da dinâmica mais complexa da capital fluminense, essas representações paramilitares, embora consigam alcançar de forma direta o poder legislativo, têm sua força política diluída frente a outros agentes. Na Baixada Fluminense, por sua vez, esses grupos violentos podem se desenvolver politicamente sem nenhum contraponto significativo, pois além de se constituírem a partir da violência, em alguns municípios os grupos paramilitares são, também, a principal força econômica local.

Weber (1968) assevera que quem tivesse aversão à violência deveria se manter distante da política. A prática destacada nesse artigo enfatizou que inúmeros agentes políticos com atuação na supracitada região apresentam estreita relação com a violência e, por essa razão, não exemplificam antipatia a esse instrumento. Contudo, para o sociólogo alemão, a violência seria a base do Estado, uma vez que esse atributo seria o único capaz de singularizar o Estado frente as demais esferas. Por extensão, a premissa weberiana é subvertida por parte dos agentes políticos que conquistam cargos eletivos na Baixada Fluminense. A violência que eles praticam de forma privatista é monopólio do Estado ao qual eles passam a servir e, nesse sentido, suas práticas estão em desacordo como a instituição que representa.

Todavia, não se deve exigir coerência de uma tipologia de poder calcada nessa forma de coação, pois ela permite controlar mais pessoas do que àquela assentada sobre a persuasão. Isso porque as exposições de ideias, atividade necessária na tentativa de persuasão, possui limites decorrentes da ideologia do público para o qual os argumentos se direcionam, já a bala de um fuzil, por exemplo, não dialoga: atinge a todos e com o mesmo efeito, independentemente de suas crenças políticas. 


\section{Referências Bibliográficas}

ALVES, José Cláudio Souza. (1994) Baixada Fluminense: a violência na construção de uma periferia. [S.L.: s.n.].

(2003) Dos Barões ao Extermínio: Uma História da Violência na Baixada Fluminense. Duque de Caxias, RJ: APPH-CLIO.

(2005) Violência e política na Baixada: o caso dos grupos de extermínio. In: Documento Impunidade na Baixada Fluminense. Rio de Janeiro: [s.n.].

(2015) Baixada Fluminense: reconfiguração da violência e impactos sobre a educação. Revista Movimento. Niterói, Faculdade de Educação-Programa de Pós-graduação em Educação, UFF, Ano 2, № 3.

ARENDT, Hannah. (2016) Sobre a Violência. Rio de Janeiro: Civilização Brasileira.

BAUMAN, Zygmunt. (2009) Confiança e medo na cidade. Rio de Janeiro: Jorge Zahar.

CORRÊA, Roberto Lobato. (2011) Trajetórias geográficas. Rio de Janeiro: Bertrand Brasil.

FOUCAULT, Michel. (2016) Microfísica do poder. Organização e tradução de Roberto Machado. Rio de Janeiro: Paz e Terra.

FUNDREM. (1979) Plano diretor das unidades urbanas integradas de oeste. Rio de Janeiro: Fundrem.

GEIGER, Pedro Pinchas; SANTOS, Ruth Lyra. Notas Sobre a Evolução da Ocupação Humana da Baixada Fluminense. Rio de Janeiro: IBGE, 1956. Separata da Revista Brasileira de Geografia. Rio de Janeiro, no 3- Ano XVI, jul./set. 1955.

LAMEGO, Alberto Ribeiro. (1964) O homem e a Guanabara. Rio de Janeiro: Biblioteca Geográfica Brasileira/IBGE.

LEAL, Victor Nunes. (1997) Coronelismo, Enxada e Voto: o município e o regime representativo no Brasil. Rio de Janeiro: Nova Fronteira.

MELGAÇO, Lucas de Melo. (2010) Securização Urbana: da psicoesfera do medo à tecnoesfera da segurança. 274 f. Tese (Doutorado em Geografia Humana) - Departamento de Geografia da Faculdade de Filosofia, Letras e Ciências Humanas da Universidade de São Paulo, São Paulo.

ODALIA, Nilo. (1991) O que é violência. São Paulo: Editora Brasiliense.

O GLOBO. Valorização e aproveitamento do campo para a salvação das cidades. Jornal O Globo, Rio de Janeiro, 22 jul. 1952, p. 7.

. O País inteiro contra o Esquadrão da Morte. Jornal O Globo, Rio de Janeiro, 8 mar. 1969, p. 17.

. A organização acabou, o crime continua. Jornal O Globo, Rio de Janeiro, 29 out. 1972, p. 7.

Geisel manda apurar os casos de fuzilamentos na Baixada. Jornal O Globo, Rio de Janeiro, 28 ago. 1974, Caderno Grande Rio, p. 7.

Delegado atribui crimes da Baixada à "polícia mineira". Jornal O Globo, Rio de Janeiro, 29 jul. 1977, Caderno o Estado do Rio, p. 13.

Brum Negreiros: esquadrão da morte já está na cadeia. Jornal O Globo, Rio de Janeiro, 23 fev. 1978, Caderno Grande Rio, p. 15.

BBC: cresce violência no Rio. Jornal O Globo, Rio de Janeiro, 25 nov. 1989, Caderno Grande Rio, p. 14.

OLIVEIRA, Rafael da Silva. (2004) Distintas noções de Baixada Fluminense: a busca do entendimento da constituição política da região - apresentação otimista sobre o crescimento latente. In: estudos e desafios. Rio de Janeiro: Paradigma Editora. (org). Baixada Fluminense: Novos

OLIVEIRA, Raimundo Jovanil Pereira. (2016) Do medo da violência à violência do medo: uma reflexão sobre os impactos sócio-político-espaciais da violência em Fortaleza. 2016. 117 f. Dissertação de mestrado. Centro de Humanidades, Mestrado Acadêmico em Políticas Públicas e Sociedade, Universidade Estadual do Ceará, Fortaleza.

PACHECO, Susana Mara Miranda. (1984) Produção e Reprodução de Loteamentos na Periferia do Rio de Janeiro. 1984, 218p. Tese (Doutorado). Instituto de Geociências- Universidade Federal do Rio de Janeiro, Rio de Janeiro.

PEREIRA, Paulo Cesar. "Justiçamento", uma tradição na Baixada. Jornal O Globo, Rio de Janeiro, 26 nov. 1981, Caderno 
Especial, p. 33.

ROCHA, André Santos. (2009) Baixada Fluminense: representações espaciais e disputas de legitimidades na composição territorial municipal. 2009, 141p. Dissertação (Mestrado). Programa de Pós-Graduação em Geografia- Universidade Federal Fluminense, Niterói. Território como representação. Revista Mercator, v. 12, n. 29, p. 139-153, set./dez. 2013.

SEGADAS SOARES, Maria Therezinha de. Nova Iguaçu: absorção de uma célula urbana pelo grande Rio de Janeiro. Revista brasileira de Geografia. Rio de Janeiro, Ano 24, № 2, pp.157-241, Abr/jun. 1962.

SOARES, Luiz Eduardo (1996). O inominável, nosso medo. In: SOARES, Luiz Eduardo et al. Violência e política no Rio de Janeiro. Rio de Janeiro: Relume Dumará: ISER.

SOUTO, Adriana Branco Correia. (2016) As Comissões Federais de Saneamento da Baixada Fluminense (1910/1933). 2016. 142 p. Dissertação (Mestrado em Desenvolvimento Territorial). Instituto de Ciências Sociais e Aplicadas, Universidade Federal Rural do Rio de Janeiro, Nova Iguaçu, RJ.

STOPPINO, Mário. Violência. In. BOBBIO, Norberto; MATTEUCCI, Nicola; PASQUINO, Gianfranco. (1998) Dicionário de Política. Vol. 1. Brasília: Editora UNB.

VIANA, Oliveira. (1987) Instituições políticas brasileiras. Belo Horizonte: Itatiaia; São Paulo: Editora da Universidade de São Paulo; Niterói, RJ: Editora da Universidade Federal Fluminense.

WEBER, Max. (1968) Ciência e Política: duas vocações. Rio de Janeiro: Editora Cultrix.

ZALUAR, Alba. (1999) Um debate disperso: violência e crime no Brasil da redemocratização. In: São Paulo em perspectiva, São Paulo, v. 13, n. 3, p. 3-17, set. 